\title{
La profecía de la encíclica Populorum progressio
}

\author{
JOSÉ ROMÁN FLECHA ANDRÉS* \\ Comité Científico del Istituto Paolo VI (Italia) \\ jrflechaan@upsa.es
}

\section{Resumen}

Fiel a la reflexión del Concilio Vaticano II y escuchando las voces de los pueblos más pobres, Pablo VI publicó la encíclica Populorum progressio, como un valiente "manifiesto" sobre el humanismo del progreso integral. La observación de los signos de los tiempos y la fidelidad al mensaje evangélico hacen que esta encíclica pueda ser leída como una amplia catequesis sobre la caridad social y, mejor aún, como una voz profética para nuestro tiempo.

Palabras clave: Antropología, desarrollo, dualismo, moral social, pobreza, profecía, progreso.

\section{The prophecy of the encyclical Populorum progressio}

\begin{abstract}
Faithful to the message of the II Vatican Council and listening to the voices of the poorest people, Paul VI published the encyclical Populorum Progressio as a courageous "manifesto" on the humanism of integral progress. Observing the signs of the times and fidelity to the Gospel message make this encyclical read as a broad catechesis on social charity and, even better, as a prophetic voice for our time.
\end{abstract}

Keywords: Anthropology, development, dualism, social ethics, poverty, prophecy, progress.

Catedrático de Teología Moral en la Facultad de Teología de la Universidad Pontificia de Salamanca. Ha publicado un gran número de obras entre las que cabe mencionar Teología Moral Fundamental (1997), La vida en Cristo. Fundamentos de la moral cristiana (2000), El respeto a la creación (2001), Moral de la Persona (2002), Vida cristiana, vida teologal. Para una moral de la virtud (2002), Moral Fundamental. La vida según el Espiritu (2005), Bioética. La fuente de la vida (2005), Moral Social. La vida en comunidad (2007), Las Bienaventuranzas. Caminos de felicidad (2011) y Las obras de Misericordia (2016). 


\section{LA PREOCUPACIÓN POR LA PAZ}

A cualquier observador de la enseñanza pontificia le llamará la atención tanto la continuidad como las diferencias que se pueden encontrar entre el magisterio de Pablo VI ${ }^{1}$ y el de sus inmediatos predecesores. Seguramente hay un hilo conductor que depende tanto de la situación mundial como de la fidelidad al evangelio: la preocupación por la paz.

\subsection{Pío XII y Juan XXIII}

Es evidente que el papa Pío XII tuvo que ofrecer una respuesta tanto a los dramáticos problemas de la guerra cuanto a los numerosos interrogantes que planteaba el horizonte del nuevo orden internacional. Pero nunca desaprovechó la ocasión para ofrecer a los fieles una orientación moral sobre los pasos que incesantemente daban tanto la investigación científica con relación a la vida humana como la práctica técnica consiguiente.

Como se sabe, el magisterio del papa Pacelli se desarrolló fundamentalmente a través de sus importantes mensajes radiofónicos y también a lo largo de los numerosos discursos que dirigió a los más variados grupos de científicos. Ciertamente había de referirse con frecuencia a los problemas relativos a la guerra, a la paz y al nuevo orden social que era preciso reconstruir desde sus cimientos.

Pues bien, en el célebre radiomensaje para la Navidad de 1942, entre las cinco "piedras miliarias" que Pío XII proclamaba como necesarias y urgentes para conseguir la paz, aludía expresamente al progreso y al grado de las reformas sociales improrrogables, que dependen de la potencia económica de cada nación. Según él, "sólo con un intercambio de fuerzas, inteligente y generoso, entre los fuertes y los débiles, será posible llevar a cabo una pacificación universal de forma que no queden focos de incendio y de infección, de los que podrían originarse nuevas catástrofes".

Por otra parte, el magisterio de su sucesor el papa Juan XXIII quedó marcado por sus dos encíclicas sociales, Mater et Magistra [AAS 53 (1961) 401-464] y Pacem in terris [AAS 55 (1963) 257-304], así como por sus alocuciones, orientadas especialmente a la preparación del Concilio Vaticano II.

1 Durante el primer año de su pontificado, Pablo VI se refirió al menos catorce veces al papa Pío XII. Es muy interesante el discurso que pronunció con motivo de la inauguración en la Basílica de San Pedro del monumento a él dedicado, obra del escultor Francesco Messina. En esa ocasión defendió la memoria de Pío XII contra las indignas acusaciones que circulaban sobre su obra y su comportamiento con relación a los judíos (12.3.1964). 
En la primera de esas encíclicas aparecía ya el concepto del desarrollo, del que se venían ocupando las ciencias económico-sociales al menos desde el año 1940 (Clark, 1940; Adroer, 1968; Dower, 1998). En la Mater et Magistra se llamaba la atención de todos sobre un precepto gravísimo de la justicia social, a saber: que "el desarrollo económico y el progreso social deben ir juntos y acomodarse mutuamente, de forma que todas las categorías sociales tengan participación adecuada en el aumento de la riqueza de la nación" (MM, 73).

En la encíclica Pacem in terris el papa Roncalli escribía que "es necesario que los gobiernos pongan todo su empeño para que el desarrollo económico y el progreso social avancen al mismo tiempo y para que, a medida que se desarrolla la productividad de los sistemas económicos, se desenvuelvan también los servicios esenciales" (PT, 64). Al mismo tiempo, el Papa dejaba a la Iglesia y a la humanidad la tarea de repensar los grandes valores necesarios para la construcción de la paz y de la justicia social (Flecha, 2007).

De alguna forma se puede encontrar en numerosos gestos la herencia que Juan XXIII dejaba a su sucesor, Pablo VI, con el que le unían tantos lazos de origen, de amistad y de afinidad espiritual (Maffeis, 2014).

\subsection{El magisterio de Pablo VI}

Es evidente que el magisterio de Pablo VI sobre las cuestiones éticas emergentes, sobre la paz y el progreso humano, se encuentra sobre todo en lo que podríamos denominar como sus documentos mayores, es decir, en sus encíclicas, en su carta Octogesima Adveniens y en sus exhortaciones, como la célebre Evangelii nuntiandi (Flecha, 1996).

Entre las seis encíclicas que publicó, en este momento es preciso tener en cuenta especialmente la Ecclesiam suam (6.8.1964) y la Populorum progressio (26.3.1967).

Con relación a la encíclica Ecclesian suam [AAS 56 (1964) 609-659]; (Colombo, 2015), es interesante recordar la audiencia general del miércoles 5 de agosto de 1964, celebrada en Castel Gandolfo ${ }^{2}$. En la alocución que aquel día dirigió a los peregrinos afirmaba Pablo VI con un cierto humor que se podría decir que aquella era la primera conferencia de prensa que ofrecía un papa. La noticia que deseaba presentar era que había terminado la redacción de su primera carta encíclica, Ecclesiam Suam, que llevaría la fecha del día siguiente, fiesta de la Transfiguración del Señor. $60)$. 
Según él, aquella encíclica venía a sugerir lo que debía hacer la Iglesia para ser fiel a su vocación y para adaptarse a su misión en el mundo. Es decir, en aquel documento se exponía la metodología que la Iglesia debería seguir para caminar según la voluntad de Cristo. Así que su mensaje podría resumirse con el título de "Los caminos de la Iglesia". Un camino señalado por tres palabras clave: la conciencia, la renovación y el diálogo.

De esta forma, como él mismo manifestaría en el discurso con el que inauguraba la tercera sesión del Concilio, el Papa evitaba entrar en las grandes cuestiones que había de tratar la asamblea conciliar, pero, al mismo tiempo, ofrecía al episcopado y a todo el pueblo cristiano algunos criterios imprescindibles para estudiarlas y actuarlas a la luz de Cristo y bajo la guía del Espíritu Santo (Gallagher, 2016).

Es evidente que Pablo VI estaba tan preocupado por el advenimiento de la paz como sus predecesores. Bastaría recordar el importante discurso pronunciado por él ante la asamblea general de las Naciones Unidas. Es imposible olvidar el tono con el que pedía a los representantes de todo el mundo que llevasen a las naciones no a caminar las unas contra las otras, sino a actuar las unas a favor de las otras. Para lograrlo, según la profecía de Isaías, era necesaria convertir las espadas en rejas de arado y las lanzas, en podaderas, como ha sido recordado por la estatua de bronce que se levanta a la entrada del edificio de la ONU en la ciudad de Nueva York. Con razón clamaba el Papa que se abandonaran las armas: “iNunca más la guerra! (Pancirolli, 2001; Durand, 2004).

De todas formas, se ha subrayado el cambio epistemológico que se puede descubrir al confrontar la encíclica Pacem in terris con la encíclica Populorum progressio (Lo Presti, 2015). Vistas las cosas a distancia de años, se comprende que es imposible entender verdaderamente a Pablo VI sin tener en cuenta su encíclica Populorum progressio, que, con toda razón, ha sido calificada como "el documento destinado a marcar la historia del pontificado" (Tornielli, 2009: 453; Acerbi, 1989). En ella se encuentra su profética propuesta de un nuevo humanismo (Campanini, 1989).

\subsection{La publicación de la Populorum progressio}

El Concilio Vaticano II había respondido varias veces a la tópica acusación, según la cual los cristianos, por haber dirigido su mirada hacia el cielo, habrían olvidado este suelo y por tanto el ansia de progreso y desarrollo de todos los pueblos (GS, 21, 31, 39; Flick, 1966). Según el Concilio, los cristianos no piensan que las conquistas logradas por el hombre se oponen al poder de Dios. Al contrario, afirman que las victorias del hombre responden al proyecto de Dios y manifiestan su grandeza (GS, 34). 
Pues bien, el día 28 de marzo del año 1967 el papa Pablo VI publicaba su encíclica Populorum progressio sobre la necesidad de promover el desarrollo de los pueblos. El documento llevaba la fecha del día 26, en el que se había celebrado la fiesta de Pascua. Esa elección era intencionada. Con ella el Papa quería indicar que la promoción del desarrollo de los pueblos pobres no podía ser considerada desde la perspectiva del oportunismo económico, sino que se convertía en un deber moral, motivado directamente por la fidelidad al evangelio. La palabra de la Iglesia sobre la promoción del ser humano encontraba sus raíces en la resurrección de Jesucristo (Álvarez Bolado, 1968).

La idea no era nueva en la mente y en el programa del papa Montini, profundamente preocupado por las cuestiones sociales (Gutiérrez García, 1984). Se sabe que ya desde el año 1963 venía él recogiendo materiales sobre el tema, conservados en un dossier que llevaba por título Sullo sviluppo economico, sociale, morale. Materiale di studio per una enciclica sui principi morali dello sviluppo umano. Aquel material se enriquecía con el pensamiento de Jacques Maritain y con el testimonio de las decisiones pastorales de monseñor Manuel Larraín Errázuriz, obispo de Talca, en Chile ${ }^{3}$. El primer proyecto se remonta a septiembre de 1964, y el séptimo y último se concluyó el 16 de febrero de 1967.

Como se sabe, el texto fue elaborado en sus primeras fases por el P. Lebret hasta su muerte ocurrida en el año 1966. Se ha escrito que se podrían encontrar muchas citas puntuales de los esquemas y escritos del P. Lebret a lo largo de los 87 párrafos de la encíclica (De Rita, 1989).

Había pasado un año y medio desde la clausura del Concilio Vaticano II, al final de la cual, Pablo VI había entregado a representantes de diversos grupos sociales los famosos mensajes en los que se reflejaba el interés del Concilio por la amplia actividad humana. Era el momento de pensar en los problemas y las promesas que suscitaba en la humanidad el ideal del progreso.

Es preciso subrayar el peso que, en quince referencias explícitas, la encíclica concede a la Constitución pastoral Gaudium et spes, sobre la Iglesia en el mundo de hoy. El Papa que ha sido calificado como el gran timonel del Concilio Vaticano II, no podía menos de evocar aquel texto aprobado por la asamblea conciliar el día 7 de diciembre de 1965, precisamente en la víspera de la clausura del Concilio.

Tornielli (2009: 453-454), quien cita al cardenal Poupard (1997), así como a Coste (1989). 
La encíclica, que exigía prestar una mayor atención y una ayuda global y eficaz al proceso de los pueblos en vías de desarrollo se situaba precisamente entre la euforia de los famosos "dorados años sesenta" y la revolución que iba a recorrer los escenarios universitarios del mundo occidental.

\section{NOVEDAD PROFÉTICA DE LA ENCÍCLICA}

Como se sabe, la encíclica Populorum progressio está articulada en dos partes bien diferenciadas, precedidas de un interesante preámbulo.

Con un tono que evoca la cercanía conciliar al mundo, sus progresos y sus problemas, se afirma en el preámbulo que la Iglesia observa con atención "el desarrollo de los pueblos y muy especialmente el de aquellos que se esfuerzan por escapar del hambre, de la miseria, de las enfermedades endémicas, de la ignorancia; que buscan una más amplia participación en los frutos de la civilización, una valoración más activa de sus cualidades humanas; que se orientan con decisión hacia el pleno desarrollo" (PP, 1).

Evidentemente esa atención no se debe a una intención de promoción o de imagen. Es el evangelio de Jesucristo el que obliga a la Iglesia a ponerse al servicio de los hombres, como ya habían subrayado los papas anteriores, desde León XIII a Juan XXIII. Las dos encíclicas sociales de este Papa habían recordado que los pueblos hambrientos interpelan a los pueblos opulentos, con una voz que no puede ser ignorada por la Iglesia (PP, 3).

Pablo VI recuerda sus viajes a Latinoamérica y África, a Tierra Santa y a la India, así como su mencionada visita a la sede de las Naciones Unidas (Rossi, 2004). Sus contactos con la pobreza le ayudaron a hablar como abogado de los pueblos pobres (PP, 4). En el mismo contexto, había decidido crear la Comisión Pontificia "Justicia y Paz" con el fin de promover la reflexión y la acción sobre esos dos grandes valores, que deberían suscitar la colaboración de todos los hombres de buena voluntad (PP, 5).

La gran novedad de la encíclica consistía en aquella admirable pasión y compasión con que el papa Montini deseaba propugnar y promover el progreso integral. Con toda razón advertía que el progreso había de alcanzar a todo el hombre y a todos los hombres (PP, 14). Fiel a la reflexión conciliar, Pablo VI pensaba que era un error valorar el progreso técnico, si se olvidaba la maduración interior de la persona. Y no era justo promover el desarrollo de algunos pueblos o sectores de la sociedad si se dejaba marginados a muchos otros.

Por otra parte, ya desde el mismo encabezamiento de la encíclica llamaba poderosamente la atención el hecho de que fuera dirigida no solo a los obispos, sacerdotes, religiosos y fieles de todo el mundo, sino también 
a todos los hombres de buena voluntad. Esta dedicatoria universal determina, a su vez, la elección de un estilo novedoso, directo, casi periodístico, que ha llevado a algunos a calificar esta encíclica como un "manifiesto" (García, 1968).

Pues bien, en su encíclica Pablo VI afirmaba que "en los designios de Dios, cada hombre está llamado a promover su propio progreso, porque la vida de todo hombre es una vocación dada por Dios para una misión concreta" (PP, 15).

En la primera parte de la encíclica, el Papa analiza la esencia y el sentido del desarrollo integral del hombre. Para promoverlo de verdad, es preciso superar dos reduccionismos bastante habituales. En primer lugar, el que sólo valora el progreso material e ignora el espiritual. Y después, el que sólo trata de promover el progreso para algunos seres humanos, olvidando a los demás. La auténtica alternativa consiste en promover el progreso integral, es decir el progreso "para todo el hombre y para todos los hombres"4.

En la segunda parte de la encíclica, Pablo VI señala algunas urgencias inesquivables para poder recorrer el camino hacia el desarrollo solidario de la humanidad. Ese camino pasa por una mayor asistencia a los débiles, por la garantía de la equidad en las relaciones comerciales y por los deberes que exige el mandato e ideal de la caridad universal.

Hay en esta encíclica algunas frases que son inolvidables. Como ésta que nos lleva a reflexionar sobre lo esencial del progreso: "El mundo está enfermo. Su mal está menos en la esterilidad de los recursos y en su acaparamiento por parte de algunos que en la falta de fraternidad entre los hombres y entre los pueblos" (PP, 66). Evocando la encíclica Ecclesiam suam, escribe Pablo VI que tanto "entre las civilizaciones, como entre las personas, un diálogo sincero es creador de fraternidad" (PP, 73). Para lograr ese ideal, hay que postular una autoridad mundial eficaz que pueda despertar y que promueva la esperanza de un mundo mejor (PP, 78).

El Papa afirmaba, finalmente, que "la hora de la acción ha sonado ya; la supervivencia de tantos niños inocentes, el acceso a una condición humana de tantas familias desgraciadas, la paz del mundo, el porvenir de la civilización, están en juego. Todos los hombres y todos los pueblos deben asumir sus responsabilidades" (PP, 80). De hecho, no solo presen-

\footnotetext{
4 Esa frase había de hacer fortuna. De hecho, sería citada por Benedicto XVI en su discurso inaugural a la Conferencia General del Episcopado Latinoamericano y del Caribe, celebrada en Aparecida (13.5.2007), y se encontraría hasta siete veces en su carta encíclica Caritas in veritate.
} 
taba él un panorama de las desigualdades sociales y del reduccionismo antropológico del progreso, sino que ofrecía una interpretación del mismo a la luz de la fe.

\section{UNA CATEQUESIS SOBRE EL PROGRESO}

Si bien se observa la estructura de la encíclica Populorum progressio, su primera parte parece articulada según el clásico esquema del análisis de la realidad, resumido habitualmente en el trinomio "ver, juzgar y actuar".

\subsection{Datos sobre el subdesarrollo}

En una primera sección, Pablo VI se detiene a recoger los datos básicos del problema del subdesarrollo. A simple vista se descubre que son muchas las personas que ven frustrados sus deseos más legítimos, como "verse libres de la miseria, hallar con más seguridad la propia subsistencia, la salud, una ocupación estable; participar todavía más en las responsabilidades, fuera de toda opresión y al abrigo de situaciones que ofenden su dignidad de hombres; ser más instruidos; en una palabra, hacer, conocer y tener más para ser más" (PP, 6).

Este deseo de avanzar en el progreso es especialmente urgente en los pueblos que han logrado recientemente su independencia nacional (PP, 6). Tras subrayar las ambigüedades del colonialismo y de sus consecuencias (Cencillo, 1968), señala la encíclica que la herencia recibida de los países colonizadores es ya insuficiente para enfrentarse a la economía moderna. "Los pueblos ricos gozan de un rápido crecimiento, mientras que los pobres se desarrollan lentamente. El desequilibrio crece: unos producen con exceso géneros alimenticios que faltan cruelmente a otros, y estos últimos ven que sus exportaciones se hacen inciertas" (PP, 8).

Como se sabe, esta observación sobre la brecha que separa a unos países de otros sería ampliamente criticada. Sin embargo, el tiempo transcurrido desde la aparición de la encíclica le ha dado la razón más que sobradamente.

Por otra parte, el Papa señala que, mientras que es cada vez más amplia la toma de conciencia de las desigualdades sociales, se añade el escándalo de las disparidades existentes tanto en el goce de los bienes como en el ejercicio del poder (PP, 9).

A esto se une el choque entre la tradición y los desafíos de la civilización industrial. "El conflicto de las generaciones se agrava así con un trágico dilema: o conservar instituciones y creencias ancestrales y renunciar al progreso; o abrirse a las técnicas y civilizaciones que vienen de fuera, pero rechazando con las tradiciones del pasado toda su riqueza humana. 
De hecho, los apoyos morales, espirituales y religiosos del pasado ceden con mucha frecuencia, sin que por eso mismo esté asegurada la inserción en el mundo nuevo" (PP, 10).

Como es fácil imaginar, todos estos datos presentan el peligro de reacciones populares violentas, de agitaciones insurreccionales y de peligrosos deslizamientos hacia las ideologías totalitarias.

\subsection{La Iglesia y el desarrollo}

En una segunda sección, que podría situarse bajo el clásico epígrafe del "juzgar", Pablo VI resume la acción y la enseñanza de la Iglesia con relación al desarrollo.

Por lo que se refiere a la acción, el Papa recuerda la labor de los misioneros, que fieles al mensaje de Jesús, han anunciado por todas partes la Buena Nueva a los pobres $(\operatorname{Lc} 7,22)$. De hecho, "la Iglesia nunca ha dejado de promover la elevación humana de los pueblos, a los cuales llevaba la fe en Jesucristo. Al mismo tiempo que iglesias, sus misioneros han construido hospicios y hospitales, escuelas y universidades". Aun reconociendo que la acción misional no siempre ha sido perfecta, ha sabido cultivar y promover las instituciones locales, promoviendo el progreso material y la elevación cultural (PP, 12).

De todas formas, reconoce el Papa que en el próximo futuro ya no bastarán las iniciativas locales e individuales. "La presente situación del mundo exige una acción de conjunto que tenga como punto de partida una clara visión de todos los aspectos económicos, sociales, culturales y espirituales" (PP, 13).

La Iglesia trata de establecer en la tierra el reino de los cielos y no pretende conquistar un poder terrenal. Es evidente la diferencia que existe entre los dos campos. Pero citando el Concilio (GS, 4), afirma el Papa que la Iglesia es consciente de que en su misión se incluye el deber de "escrutar a fondo los signos de los tiempos e interpretarlos a la luz del Evangelio".

Es notable la importancia que la cultura adquiere en el magisterio de Pablo, hasta encontrar una explicitación en la exhortación Evangelii nuntiandi (Caprioli \& Vaccaro, 1983; Colombo, 2015; Canobbio, 2016: 345350). Sin embargo, tanto en la encíclica Ecclesiam suam como en la Populorum progressio se encuentran ya los gérmenes de su enseñanza sobre el tema. En este contexto, es preciso retomar las palabras con las que se resume la gran aportación de la Iglesia a la cultura de hoy y a la sociedad de todos los tiempos: "Tomando parte en las mejores aspiraciones de los hombres y sufriendo al no verlas satisfechas, la Iglesia desea ayudarles a conseguir su pleno desarrollo. En el intento de conseguirlo, la Iglesia les propone lo que 
ella posee como propio: una visión global del hombre y de la humanidad" (PP, 13).

Pues bien, a la luz de la antropología cristiana y de esa cultura humanista que ella propone, se puede comprender que "el desarrollo no se reduce al simple crecimiento económico. Para ser auténtico, debe ser integral, es decir, promover a todos los hombres y a todo el hombre" (PP, 14).

Esta es, sin duda una de las aportaciones más notables de la encíclica. Es su novedad profética. El progreso verdadero ha de superar tanto el dualismo antropológico que reduce a la persona a su dimensión corpórea o a la espiritual -tentación que ya había denunciado el Concilio (GS, 3)-, como el dualismo social que valora a algunos individuos relegando a otros al anonimato. La otra gran aportación es la visión del desarrollo como la respuesta a una vocación trascendente.

A la luz de la fe cristiana, la respuesta a esa vocación divina constituye a la vez un deber personal y comunitario. Tanto la fe en el Dios creador como la inserción del creyente en la vida de Cristo indican que el crecimiento humano constituye como un resumen de los deberes de cada uno. Más aun, esta armonía de la naturaleza, enriquecida por el esfuerzo personal y responsable, está llamada a superarse a sí misma. El hombre está llamado a un progreso nuevo, a un humanismo trascendental. Esa es la finalidad suprema del desarrollo personal (PP, 16).

Ahora bien, cada uno de los hombres es miembro de la sociedad, pertenece a la humanidad entera. Todos los hombres están llamados a este desarrollo pleno. "La solidaridad universal, que es un hecho y un beneficio para todos, es también un deber" (PP, 17).

Como es de imaginar, "este crecimiento personal y comunitario se vería comprometido si se alterase la verdadera escala de valores. Es legítimo el deseo de lo necesario, y el trabajar para conseguirlo es un deber". Sin embargo, la encíclica advierte que el derecho a los bienes temporales no debe llevar a las personas o a los grupos sociales a ceder al deseo de tener cada vez más y de aumentar el propio poder. "La avaricia de las personas, de las familias y de las naciones puede apoderarse lo mismo de los más desprovistos que de los más ricos, y suscitar en los unos y en los otros un materialismo sofocante" (PP, 18).

El Papa afirma que "todo crecimiento es ambivalente". Cuando el ansia de tener más se convierte en el bien supremo, los corazones se endurecen y los espíritus se cierran. En ese caso, los hombres ya no se unen por amistad, sino por interés. Recordando un pensamiento conciliar muy conocido, afirma que "la búsqueda exclusiva del poseer se convierte en un obstáculo para el crecimiento del ser". El desarrollo no está simplemente 
en la adquisición de los bienes. "Para las naciones como para las personas, la avaricia es la forma más evidente de un subdesarrollo moral" (PP, 19).

La encíclica añade una observación sobre la necesaria complementariedad entre el tecnicismo y el humanismo. Para lograr el desarrollo se necesitan técnicos, pero también pensadores que busquen un humanismo nuevo. Evocando una conferencia de Jacques Maritain sobre las condiciones espirituales del progreso y de la paz, propone el Papa un humanismo que permita al hombre moderno hallarse a sí mismo, asumiendo los valores superiores del amor, de la amistad, de la oración y de la contemplación.

Es preciso anotar que solamente en el número 21 de la encíclica se ofrece una definición del desarrollo, como "el paso, para cada uno y para todos, de condiciones de vida menos humanas a condiciones más humanas". Así pues, el progreso verdadero habrá de ayudar a la persona y a la sociedad a pasar de unas condiciones menos humanas a otras más humanas. En el párrafo siguiente señala el Papa las condiciones menos humanas y las más humanas.

- Menos humanas son las carencias materiales de los que están privados del mínimum vital y las carencias morales de los que están mutilados por el egoísmo. Menos humanas son también las estructuras opresoras, que provienen del abuso del tener o del abuso del poder, de la explotación de los trabajadores o de la injusticia de las transacciones.

- Entre las condicionas más humanas menciona el Papa la superación de la miseria, la victoria sobre las calamidades sociales, la ampliación de los conocimientos, la adquisición de la cultura. Más humanas son también la consideración de la dignidad de los demás, la orientación hacia el espíritu de pobreza, la cooperación en el bien común y la voluntad de paz. Más humano todavía es el reconocimiento de los valores supremos y de Dios, que es su fuente y su fin. Más humana, por fin es la apertura a la fe y la unidad en la caridad de Cristo (PP, 22).

\subsection{Acciones urgentes}

En una tercera sección, que podría corresponder al momento catequético del "actuar", señala el Papa una docena y media de acciones que se deben emprender con urgencia:

1. Reconocer el derecho de todos los seres humanos y de todos los pueblos a encontrar en la tierra lo que necesitan, poniéndola a su servicio, según el plan divino de la creación (PP, 22). 
2. Adquirir conciencia de que la propiedad privada no constituye para nadie un derecho incondicional y absoluto. No hay ninguna razón para reservarse en uso exclusivo lo que supera a la propia necesidad cuando a los demás les falta lo necesario (PP, 23).

3. Reconocer que el bien común exige a veces la expropiación de propiedades explotadas de forma deficiente y que las rentas provenientes de los recursos y de la actividad nacional no deben ser transferidas al extranjero por puro provecho personal (PP, 24).

4. Adquirir conciencia de que la industrialización es señal y factor del desarrollo, disciplina las costumbres, desarrolla el gusto por la investigación y la invención, la aceptación del riesgo calculado, la audacia en las empresas, la iniciativa generosa y el sentido de responsabilidad (PP, 25).

5. Denunciar el liberalismo sin freno, que conduce a la dictadura, en cuanto generador del "imperialismo internacional del dinero", ,recordando que la economía está al servicio del hombre y reconociendo la aportación irremplazable de la organización del trabajo ${ }^{5}$ y del progreso industrial a la obra del desarrollo (PP, 26).

6. Reconocer la ambivalencia del trabajo que, si bien hace al hombre con-creador y ayuda a descubrir la fraternidad humana, la conciencia profesional, el sentido del deber y la caridad para con el prójimo, también tiene el peligro de exaltar una mística exagerada del trabajo y de deshumanizar a quien lo realiza convertido en siervo suyo (PP, 27-28).

7. Procurar que la labor que hay que realizar progrese armoniosamente, tanto en la reforma agraria como en la industrialización, de forma que no se genere más miseria, se disloquen las estructuras y se engendren miserias sociales, que serían un retroceso para la humanidad (PP, 29).

8. Pensar que "cuando poblaciones enteras, faltas de lo necesario, viven en tal dependencia que les impide toda iniciativa y responsabilidad, lo mismo que toda posibilidad de promoción cultural y de participación en la vida social y política, es grande la tentación de rechazar con la violencia tan grandes injurias contra la dignidad humana" (PP, 30).

9. Comprender que "la insurrección revolucionaria -salvo en caso de tiranía evidente y prolongada que atente gravemente a los derechos fundamentales de la persona y dañe peligrosamente el bien común del país- engendra nuevas injusticias, introduce nuevos

\footnotetext{
5 Es interesante leer las múltiples intervenciones de monseñor Montini, arzobispo de Milán, sobre el mundo del trabajo: Montini, 1988.
} 
desequilibrios y provoca nuevas ruinas. No se puede combatir un mal real al precio de un mal mayor" (PP, 31) .

10. Entender que "el desarrollo exige transformaciones audaces, profundamente innovadoras. Hay que emprender, sin esperar más, reformas urgentes. Cada uno debe aceptar generosamente su papel, sobre todo los que, por su educación, su situación y su poder tienen grandes posibilidades de acción. Que, dando ejemplo, empiecen con sus propios haberes, como ya lo han hecho muchos hermanos nuestros en el episcopado" (PP, 32).

11. Difundir que "toca a los poderes públicos escoger y ver el modo de imponer los objetivos que alcanzar, las metas que hay que fijar, los medios para llegar a ella, estimulando al mismo tiempo todas las fuerzas agrupadas en esta acción común. Pero han de tener cuidado de asociar a esta empresa las iniciativas privadas y los cuerpos intermedios" (PP, 33).

12. Entender que "todo programa concebido para aumentar la producción no tiene otra razón de ser que el servicio de la persona... Decir desarrollo es preocuparse tanto por el progreso social como por el crecimiento económico... La tecnocracia del mañana puede engendrar males no menos temibles que los del liberalismo de ayer. Economía y técnica no tienen sentido si no es por el hombre, a quien deben servir" (PP, 34).

13. Ver que la educación es el primer objetivo de un plan de desarrollo. El hambre de instrucción se equipara al hambre de alimentos: un analfabeto es un espíritu subalimentado. Saber leer y escribir, adquirir una formación profesional, es recobrar la confianza en sí mismo y descubrir que se puede progresar al mismo tiempo que los demás (PP, 35).

14. Recordar que "el hombre no alcanza la plenitud de sí mismo más que dentro de la sociedad a que pertenece, y en la cual la familia tiene una función primordial"... Es preciso afirmar el valor de "la familia natural, monógama y estable, tal como los designios divinos la han concebido (cf. Mt 19, 6) y como el cristianismo la ha santificado" (PP, 36).

15. Ante la tentación de frenar el crecimiento demográfico con medidas radicales, reconocer que "es a los padres a los que les toca decidir el número de sus hijos, aceptando sus responsabilidades ante Dios, ante los hijos que ya han traído al mundo y ante la

\footnotetext{
6 Como se sabe, este texto ha sido instrumentalizado a veces como justificación de la revolución violenta, y en última instancia, de la teología de la liberación, a pesar de las repetidas explicaciones de Pablo VI. Véase Adornato, 2010: 196-197; Flecha, 2010.
} 
comunidad a la que pertenecen, siguiendo las exigencias de su conciencia, instruida por la ley de Dios auténticamente interpretada y sostenida por la confianza en él" (PP, 37).

16. Reconocer el valor de las organizaciones profesionales. "A través de la información que ellas procuran y de la formación que ellas proponen, pueden mucho para dar a todos el sentido del bien común y de las obligaciones que éste supone para cada uno" (PP, 38).

17. Afirmar que si respetan la orientación de la vida hacia su fin último, la libertad y la dignidad humanas. es útil y admisible el pluralismo de las organizaciones profesionales y sindicales (PP, 39).

18. Reconocer, además, la actividad de las diversas instituciones culturales, cuya función no es menor para el éxito del desarrollo, siempre que contengan verdaderos valores humanos (PP, 40).

19. Prevenir a los pueblos pobres frente a la tentación materialista que les viene de los pueblos ricos. "Los pueblos en fase de desarrollo deben saber escoger, discernir y eliminar los falsos bienes, que traerían consigo un descenso de nivel en el ideal humano, aceptando los valores sanos y benéficos para desarrollarlos juntamente con los suyos y según su carácter propio” (PP, 41).

Como conclusión de estas propuestas, el Papa afirma que es un humanismo pleno el que hay que promover. Un humanismo que comporte el desarrollo integral de todo hombre y de todos los hombres. Un humanismo que se abre al Absoluto en el reconocimiento de una vocación que da la idea verdadera de la vida humana. "Lejos de ser norma última de los valores, el hombre no se realiza a sí mismo si no es superándose” (PP, 42).

\section{UN PROYECTO SOLIDARIO}

La segunda parte de la encíclica Populorum progressio, lleva por título "El desarrollo solidario de la humanidad". Sin él no puede darse el desarrollo integral del ser humano. El ideal del desarrollo solidario de la humanidad exige la búsqueda de medios concretos y prácticos de organización y cooperación para poner en común los recursos disponibles y realizar así una verdadera comunión entre todas las naciones.

La fraternidad humana y sobrenatural comporta un triple aspecto: "deber de solidaridad, en la ayuda que las naciones ricas deben aportar a los países en vías de desarrollo; deber de justicia social, enderezando las relaciones comerciales defectuosas entre los pueblos fuerte y débiles; deber de caridad universal, por la promoción de un mundo más humano para todos, en donde todos tengan que dar y recibir, sin que el progreso de los 
unos sea un obstáculo para el desarrollo de los otros". Esos tres deberes constituyen el esquema sobre el cual se articula esta segunda parte.

\subsection{La asistencia a los débiles}

En primer lugar, el valor de la solidaridad exige una decidida lucha contra el hambre que aflige a tantos hombres y mujeres y especialmente a los niños. Pero "no se trata sólo de vencer el hambre, ni siquiera de hacer retroceder la pobreza. El combate contra la miseria, urgente y necesario, es insuficiente. Se trata de construir un mundo donde todo hombre, sin excepción de raza, religión, o nacionalidad, pueda vivir una vida plenamente humana, emancipado de las servidumbres que le vienen de la parte de los hombres y de una naturaleza insuficientemente dominada".

Esa decisión sugiere una serie de preguntas que resultan verdaderamente interpelantes para cada uno de nosotros “¿Está dispuesto a sostener con su dinero las obras y las empresas organizadas en favor de los más pobres? ¿A pagar más impuestos para que los poderes públicos intensifiquen su esfuerzo para el desarrollo? ¿A comprar más caros los productos importados a fin de remunerar más justamente al productor? ¿A expatriarse a sí mismo, si es joven, ante la necesidad de ayudar este crecimiento de las naciones jóvenes?” (PP, 47).

Ahora bien, no se puede olvidar que el deber de solidaridad afecta no solo a las personas sino también a los pueblos. "Ante la creciente indigencia de los países subdesarrollados, se debe considerar como normal el que un país desarrollado consagre una parte de su producción a satisfacer las necesidades de aquéllos; igualmente normal que forme educadores, ingenieros, técnicos, sabios que pongan su ciencia y su competencia al servicio de ellos" (PP, 48).

Eso significa que "lo superfluo de los países ricos debe servir a los países pobres. La regla que antiguamente valía en favor de los más cercanos, debe aplicarse hoy a la totalidad de las necesidades del mundo" (PP, 49). Para lograrlo habrá que hacer "estudios profundos, fijar los objetivos, determinar los medios, aunar los esfuerzos, a fin de responder a las necesidades presentes y a las exigencias previsibles" (PP, 49).

Subrayando sus ventajas, su urgencia y su necesidad, el Papa propugna "una colaboración mundial, de la cual un fondo común sería al mismo tiempo símbolo e instrumento, permitiría superar las rivalidades estériles y suscitar un diálogo pacífico y fecundo entre todos los pueblos" (PP, 5054). Es verdad que este esfuerzo de diálogo y cooperación no será fácil. "Esta obra común no irá adelante, claro está, sin un esfuerzo concentrado, constante y animoso. Pero que cada uno se persuada profundamente: está 
en juego la vida de los pueblos pobres, la paz civil de los países en vía de desarrollo y la paz del mundo" (PP, 55).

\subsection{Justicia y comercio}

El segundo de los deberes se centra en la promoción de la justicia social en las relaciones comerciales.

Efectivamente, "los esfuerzos, realmente considerables, que se han hecho para ayudar en el plano financiero y técnico a los países en vía de desarrollo, serían ilusorios si sus resultados fuesen parcialmente anulados por el juego de las relaciones comerciales entre países ricos y países pobres" (PP, 56). En la encíclica se expone de forma tan resumida como impactante el creciente desequilibrio entre los precios estables de los productos agrícolas y los precios siempre crecientes de los productos elaborados. De ahí que "los pueblos pobres permanecen siempre pobres y los ricos se hacen cada vez más ricos” (PP, 57).

¿Qué decir de la regla del libre cambio? Según la encíclica, "sus ventajas son evidentes cuando las partes no se encuentran en condiciones demasiado desiguales de potencia económica: es un estímulo del progreso y recompensa el esfuerzo. Por eso los países industrialmente desarrollados ven en ella una ley de justicia. Pero ya no es lo mismo cuando las condiciones son demasiado desiguales de país a país: los precios que se forman 'libremente' en el mercado pueden llevar consigo resultados no equitativos. Es, por consiguiente, el principio fundamental del liberalismo, como regla de los intercambios comerciales, el que está aquí en litigio" (PP, 58).

Así que "una economía de intercambio no puede seguir descansando sobre la sola ley de la libre concurrencia, que engendra también demasiado a menudo una dictadura económica. El libre intercambio sólo es equitativo si está sometido a las exigencias de la justicia social" (PP, 59).

Si en la economía nacional, se han actuados políticas fiscales y sociales para sostener a los sectores menos favorecidos, hay que propugnar medidas semejantes en las relaciones comerciales entre países ricos y países pobres. "Sin abolir el mercado de concurrencia, hay que mantenerlo dentro de los límites que lo hacen justo y moral, y, por tanto, humano" (PP, 6061).

Claro que para intentar lograr estos objetivos de justicia, hay que tratar de superar algunos serios obstáculos como el nacionalismo y el racismo. "El nacionalismo aísla los pueblos en contra de lo que es su verdadero bien". Y el racismo es un fermento de división y de odio cuando individuos y familias se ven injustamente sometidos a un régimen de excepción por razón de su raza o de su color (PP, 62-63). 
Si los pueblos en vías de desarrollo han de procurar organizarse entre ellos, las organizaciones internacionales han de reorganizarse para permitirles encontrar los medios para su progreso social y humano. Esa es la meta ideal. "La solidaridad mundial, cada día más eficiente, debe permitir a todos los pueblos el llegar a ser por sí mismos artífices de su destino" (PP, 64-65).

\subsection{La llamada a la caridad}

El tercero de los deberes que comporta la responsabilidad por el desarrollo afecta a la promoción de la caridad universal.

Según el beato Pablo VI, la raíz de las desigualdades y de la explotación de unos hombres por otros es de naturaleza moral y espiritual. He aquí una de sus frases más llamativas: "El mundo está enfermo. Su mal está menos en la esterilización de los recursos y en su acaparamiento por parte de algunos que en la falta de fraternidad entre los hombres y entre los pueblos" (PP, 66).

Es interesante comprobar que, según una tradición cristiana que se encuentra reflejada en la carta a los Hebreos (Heb 13,2), el Papa insista en el deber de la hospitalidad. Esta se refiere a los trabajadores inmigrantes y a los jóvenes estudiantes que acuden a los países avanzados para recibir una formación más cualificada pero pierden la estima de los valores espirituales de sus países de origen (PP, 67-69).

La encíclica se refiere a continuación a los industriales, comerciantes, dirigentes o representantes de las grandes empresas que, al establecerse en países en vías de desarrollo olvidan a veces el sentido social que los movía en su propio país. "Su mismo sentido de organización debería sugerirles los medios de valorizar el trabajo indígena, de formar obreros cualificados, de preparar ingenieros y mandos intermedios, de dejar sitio a sus iniciativas, de introducirles progresivamente en los puestos más elevados, disponiéndoles a sí para que en un próximo porvenir puedan compartir con ellos las responsabilidades de la dirección" (PP, 70).

Es cierto que son cada vez son más numerosos los técnicos enviados en misión de desarrollo que "saben que su competencia no les confiere una superioridad en todos los terrenos" y se esfuerzan por valorar las riquezas culturales del país que les recibe (PP, 71-72).

Ya en el primer mensaje dirigido a la entera familia humana, el 22 de junio de 1963, aunque no utilizaba la expresión "civilización del amor", Pablo VI daba a entender este su propósito universal: "El amor al prójimo, banco de prueba del amor de Dios, exige de todos los hombres una solución más equitativa de los problemas sociales, requiere procedimientos y atenciones a los países en vías de desarrollo, en los que a veces el nivel de 
vida no es digno de personas humanas. Impone un estudio decidido a escala universal para la mejora de las condiciones de vida".

En aquellas palabras se podía ya descubrir su intención de pasar de la pretensión de situarse en la Civiltà Cristiana a promover el ideal de la Civiltà dell'amore (Veneruso, 2012). No hay que olvidar el discurso con el que, el día 14 de septiembre de 1965, Pablo VI abría la cuarta sesión del Concilio Vaticano II. En aquel discurso, que ha sido calificado como un "himno al amor", el Papa Montini manifestaba que la misión de la Iglesia incluye la atención al mundo, a sus problemas y sus esperanzas. "Pero tras esto viene el amor. El amor a los hombres de hoy, tal y como son, donde estén, el amor a todos los hombres" (Martín Descalzo, 1967: 838; Colombo, 2015).

Como se sabe, en la noche de Navidad del año 1975, como fruto del Año Santo, Pablo VI había de proponer con pasión el ideal de una "civilización del amor" (Salvini, 2010).

Pues bien, en la encíclica Populorum progressio, traza ya las líneas maestras de esa civilización de amor y de paz, que habría de proponer en sus mensajes para la Jornada Mundial de la paz, por él creada en el mismo año 1967 (Joblin, 2012). De hecho, escribe Pablo VI que "entre las civilizaciones, como entre las personas, un diálogo sincero es, en efecto, creador de fraternidad. Sería deseable que gobernantes y técnicos se sintieran animados por un amor fraternal y movidos por el deseo sincero de construir una civilización de solidaridad mundial. Entonces comenzaría un diálogo centrado sobre el hombre, y no sobre los productos o sobre las técnicas. A esa tarea convoca especialmente a los jóvenes, recordándoles que "nadie puede permanecer indiferente ante la suerte de sus hermanos que todavía yacen en la miseria, presa de la ignorancia, víctimas de la inseguridad (PP, 73-74).

Evidentemente este ideal requiere de todos una oración sincera y una entrega completa a la lucha contra el subdesarrollo. "El que está animado de una verdadera caridad es ingenioso para descubrir las causas de la miseria, para encontrar los medios de combatirla, para vencerla con intrepidez" (PP, 75). La promoción de la justicia, tutelada por una eficaz autoridad mundial, es el auténtico camino del desarrollo que conduce a la paz (PP, 76-78).

A los que consideran utópico ese camino, el Papa les recuerda que son muchas las personas que quieren vivir más fraternalmente. "Este camino hacia más y mejores sentimientos de humanidad pide esfuerzo y sacrificio, pero el mismo sufrimiento, aceptado por amor hacia nuestros hermanos, es portador de progreso para toda la familia humana". De todas formas, "todos los hombres y todos los pueblos deben asumir sus responsabilidades" (PP, 79-80). 


\section{CONCLUSIÓN}

Pablo VI concluye su encíclica Populorum progressio con unos párrafos vibrantes de pasión que nos recuerdan muchas de las mejores páginas de su magisterio. En esta ocasión dirige un vigoroso llamamiento a los católicos de los países más favorecidos, a los cristianos y a los creyentes nocristianos y finamente a todos los hombres de buena voluntad conscientes de que el camino de la paz pasa por el desarrollo, a los hombres de Estado, a los pensadores y a los sabios (PP, 81-86).

Merece la pena reproducir y meditar su interpelación: "Vosotros todos los que habéis oído la llamada de los pueblos que sufren, vosotros los que trabajáis para darles una respuesta, vosotros sois los apóstoles del desarrollo auténtico y verdadero que no consiste en la riqueza egoísta y deseada por sí misma, sino en la economía al servicio del hombre, el pan de cada día distribuido a todos, como fuente de fraternidad y signo de la Providencia" (PP, 87).

La convicción del Papa quedaba esculpida en las palabras con las que llamaba a todos los hombres a unirse fraternalmente a vosotros a estos deseos y a esta acción. "Porque si el desarrollo es el nuevo nombre de la paz, ¿quién no querrá trabajar con todas las fuerzas para lograrlo?” (PP, 88).

De esa encíclica Pablo VI se hacía eco en la audiencia general del día 6 de octubre de 1976, para reafirmar la importancia que el progreso humano alcanza también a los ojos del creyente: "Nos hemos dicho ya cómo no existe en la razón profunda de las cosas una oposición radical entre fe y progreso: nuestra encíclica Populorum Progressio, entre otras afirmaciones parecidas, lo demuestra: fe y progreso, hemos dicho, son complementarios, no antitéticos de por sî". Y añadía el Papa: "Podemos ir más allá para encontrar esa mentalidad que, ignorando el verdadero orden de las cosas y de los valores, no se preocupa de la primacía del reino de Dios sobre el de la utilidad temporal. Un falso valor que se ha convertido para muchos, también cristianos, en el metro decisivo para medir por encima de cualquier otra cosa, el interés de la vida humana (cf. Mt 6,33; 1 Cor 10,33; Am 5,4-6)".

De todas formas, la encíclica Populorum progressio fue considerada como tan revolucionaria que suscitó violentas y hasta feroces acusaciones contra Pablo VI. De hecho, fue considerado como un "papa comunista", o al menos como socialista, sobre todo en los círculos económicos conservadores y en los ambientes capitalistas, mientras alcanzaba la mayor aceptación en los círculos progresistas. Sin embargo, él se mantuvo fiel a aquella línea evangélica, que se manifiesta de nuevo en su carta apostólica Octogesima adveniens (Tornielli, 2009: 454; Apeciti, 2014: 419). 
A los veinte años de la publicación de la encíclica Populorum progressio, el papa San Juan Pablo II la recordaba y alababa en su encíclica Sollicitudo rei sociales (30.12.1987), en la que la presentaba como "un documento de aplicación de las enseñanzas del Concilio" (SRS, 6). En esta ocasión subrayaba los aspectos de novedad que la Populorum progressio había venido a aportar a la doctrina social de la Iglesia (SRS, 8-10).

Al mismo tiempo señalaba que la esperanza de desarrollo, tan viva en tiempos de Pablo VI, tan solo veinte años después aparecía ya como muy lejana de la realidad (SRS, 12).

Por su parte, el Papa Francisco ha recordado en su exhortación Evangelii gandium (24.11.2013) aquel principio de discernimiento que Pablo VI proponía con relación al verdadero desarrollo: "Todos los hombres y todo el hombre" (EG, 181; PP, 14).

Más adelante, el papa Francisco cita de nuevo la encíclica de Pablo VI, al afirmar que también ahora necesitamos crecer en una solidaridad que "debe permitir a todos los pueblos llegar a ser por sí mismos artífices de su destino" (EG:190; PP:65), y que, al mismo tiempo, siempre hemos de confesar y proclamar que "cada hombre está llamado a desarrollarse" (EG, 190; PP, 15).

Finalmente, al cumplirse los cincuenta años de la publicación de la encíclica, en su discurso a los participantes en el congreso organizado por el Dicasterio para el Servicio del Desarrollo Humano Integral (3.4.2017), el mismo papa Francisco ha reflexionado hasta qué punto es actual e interpelante esa expresión del "desarrollo integral".

Estas referencias pontificias nos llevan a preguntarnos cómo ha sido la recepción de la encíclica Populorum progressio, tanto en el mundo laico como en la Iglesia. Seguramente queda mucho camino por recorrer para que la colaboración personal y estructural al progreso de las personas y de los pueblos se convierta en camino para la paz y en signo de la caridad social.

Al cumplirse los cincuenta años de la publicación de la encíclica Populorum progressio, es bueno hacer memoria de sus enseñanzas. El sueño del progreso humano no ha disminuido. Seguramente los modernos medios de comunicación lo han universalizado todavía más en estos años.

Pero no podemos quedarnos solamente en el recuerdo agradecido al beato Pablo VI. Sus intuiciones fueron verdaderamente proféticas. Y especialmente importantes también para este tiempo. 


\section{REFERENCIAS}

-Acerbi, A. (1989). I fondamenti teologici della Populorum progressio. En G. Camadini (ed.), Il magistero di Paolo VI nell'enciclica "Populorum progressio" (pp. 27-36). Brescia: Istituto Paolo VI.

-Adornato, G. (2010). Pablo VI. El coraje de la modernidad. Bogotá: San Pablo.

-Adroer, X. (1968). Evolución inmanente del concepto de desarrollo. En M. García (ed.), Teología y sociología del desarrollo. Comentario a la "Populorum progressio”. (pp. 61-71). Madrid: Editorial Razón y Fe.

-Álvarez Bolado, A. (1968). Evangelio y desarrollo. En M. García (ed.), Teología y sociología del desarrollo. Comentario a la "Populorum progressio" (pp. 73-114). Madrid: Editorial Razón y Fe.

-Apeciti, E. (2014). L'attuazione del Concilio. En X. Toscani (ed.), Paolo VI. Una biografia (pp. 419-419). Brescia-Roma: Istituto Paolo VI - Edizioni Studium.

-Campanini, G. (1989). Le radici culturali del nuovo umanesimo proposto dalla Populorum progressio. En G. Camadini (ed.), Il magistero di Paolo VI nell'enciclica "Populorum progressio" (pp. 37-53). Brescia: Istituto Paolo VI.

-Canobbio, G. (2016). La cultura. En C. Stercal (ed.), Paolo VI. Un ritratto spirituale (pp. 327-352). Brescia: Istituto Paolo VI.

-Caprioli, A. \& Vaccaro, L. (1983). Paolo VI e la cultura. Brescia: Morcelliana.

-Cárcel Ortí, V. (2014). Beato Pablo VI: Papa del diálogo. Madrid: B.A.C.

-Cencillo, L. (1968). La superación de la era colonialista. En M. García (ed.), Teología y sociología del desarrollo. Comentario a la "Populorum progressio" (pp. $37-$ 58). Madrid: Editorial Razón y Fe.

-Clark, C. (1940). The Theory of Economic Progress. London: Macmillan.

-Colombo, G. (2015). Paolo VI e il Concilio Vaticano II. Per un incontro tra teologia e pastorale. Brescia-Roma: Istituto Paolo VI - Edizioni Studium.

-Coste, R. (1989). L'enciclica Populorum progressio nel contesto del pontificato di Paolo VI. En G. Camadini (ed.), IlMagistero di Paolo VI nell'enciclica 'Populorum progressio” (pp. 15-23). Brescia-Roma: Istituto Paolo VI.

-De Rita, G. (1989). Origini culturali e fondamenti socio-economici della Populorum progressio. En G. Camadini (ed.), Il magistero di Paolo VI nell'enciclica "Populorum progressio" (pp. 151-154). Brescia-Roma: Istituto Paolo VI.

-Dower, N. (1998). Development Ethics. En R. Chadwick (ed.), Encyclopedia of Applied Ethics (vol. I, pp. 755-766). San Diego: Academic Press.

-Durand, J. D. (2004). De l'ONU à l'OIT. L'Église et la société civile dans les voyages apostoliques de Paul VI’. En R. Rossi (ed.), I viaggi apostolici di Paolo VI (pp. 201-225). Brescia: Istituto Paolo VI - Edizioni Studium.

-Flecha, J. R. (1996). Recepción del magisterio de Pablo VI en el mundo teológico español. En G. Camadini (ed.), Pablo VI y España (pp. 206-223). Brescia: Istituto Paolo VI..

-Flecha, J. R. (2007). Moral Social. La vida en comunidad. Salamanca: Sígueme.

-Flecha, J. R. (2010). Pablo VI y la teología de la liberación. En Istituto Paolo VI. Notiziario 59, 35-55. 
-Flick, M. (1966). L'attività umana e il mondo che verrà. En A. Favale (ed.), La Chiesa nel mondo contemporáneo (pp. 623-630). Torino-Leumann: Elle di Ci.

-Gallagher, M. P. (2016). The style of Paul VI and the style of Vatican II. En E. Rosanna (ed.), Il Concilio e Paolo VI. A Cinquant'anni dal Vaticano II (pp. 1224). Brescia: Istituto Paolo VI.

-García, M. (ed.) (1968). Teología y sociología del desarrollo. Comentario a la "Populorum progressio”. Madrid: Editorial Razón y Fe.

-Gutiérrez García, J. L. (1984). El magisterio social de Pablo VI. Madrid: Cete.

-Istituto Paolo VI, (1982). Ecclesiam suam. Première lettre enciclique de Paul VI. Brescia-Roma.

-Joblin, J. (2012). La construction de la communauté humaine dans 'Populorum progressio et les Messages pour les Journées de la Paix: vers la civilisation de l'amour'. En R. Papetti (ed.), Verso la civiltà dell'amore (pp. 189-226). Brescia: Istituto Paolo VI.

-Lo Presti, A. (2015). L'immaginazione rivoluzionaria: La dimensione profetica della spiritualità dei Focolari in relazione alla dottrina sociale della Chiesa di Paolo VI. En P. Siniscalco e X. Toscani (edd.), Paolo VI e Chiara Lubich. La profezia di una Chiesa che si fa dialogo (pp. 134-150). Brescia: Istituto Paolo VICentro Chiara Lubich-Edizioni Studium.

-Maffeis, A. (2014). L'eredità di Giovanni XXIII nell'azione conciliare e nel magistero di Paolo VI. En E. Bolis (ed.), Giovanni XXIII e Paolo VI. I Papi del Vaticano II (pp. 187-214). Roma: Edizioni Studium.

-Martín Descalzo, J. L. (ed.) (1967). El Concilio de Juan y Pablo. Madrid: B.A.C.

-Montini, G. B. (1988). Al mondo del lavoro. Discorsi e scritti 1954-1963. Brescia: Edizioni Studium.

-Pancirolli, R. (ed.) (2001). Paolo VI, pellegrino apostolico. Brescia: Istituto Paolo VI - Edizioni Studium.

-Poupard, P. (1997). Il trentennio della Populorum progressio. En Istituto Paolo VI. Notiziario, $\mathrm{n}^{\circ} 33$ (agosto).

-Rossi, R. (ed.) (2004). I viaggi apostolici di Paolo VI. Brescia: Istituto Paolo VI Edizioni Studium.

-Salvini, G. (ed.), (2010). Verso la civiltà dell'amore. Paolo VI e la costruzione della comunità umana. Dai discorsi e messaggi di Paolo VI (1967-1978). Pro manuscripto. Brescia: Istituto Paolo VI.

-Tornielli, A. (2009). Paolo VT. L'audacia di un Papa. Milano: Mondadori.

-Veneruso, D. (2012). Giovanni Battista Montini dal 1945 al 1978: Da una nozione di 'Civiltà cristiana' (Pio XII) a quella di una 'Civiltà dell'amore'. En Papetti, R. (ed), (2012), Verso la Civiltà dell’amore (pp. 54-92). Brescia: Istitituo Paolo VI.

Sumario: 1. La preocupación por la paz; 1.1. Pío XII y Juan XXIII; 1.2. El magisterio de Pablo VI; 1.3. La publicación de la Populorum progressio; 2. Novedad profética de la encíclica; 3. Una catequesis sobre el progreso; 3.1. Datos sobre el 
subdesarrollo; 3.2. La Iglesia y el desarrollo; 3.3. Acciones urgentes; 4. Un proyecto solidario; 4.1. La asistencia a los débiles; 4.2. Justicia y comercio; 4.3. La llamada a la caridad, 5. Conclusión; Referencias. 